\title{
Inconsistent Transmission of Banana Bunchy Top Virus in Micropropagated Bananas and its Implication for Germplasm Screening
}

\author{
J. E. Thomas, ${ }^{\mathrm{A}}$ M. K. Smith, ${ }^{\mathrm{B}}$ A. F. Kessling ${ }^{\mathrm{A}}$ and S. D. Hamill ${ }^{\mathrm{B}}$ \\ A Plant Protection Unit, Department of Primary Industries, Meiers Road, \\ Indooroopilly, Qld 4068. \\ ${ }^{B}$ Maroochy Horticultural Research Station, Department of Primary Industries, \\ P.O. Box 5083, SCMC, Nambour, Qld 4560.
}

\begin{abstract}
Banana bunchy top virus (BBTV) was readily transmitted through tissue culture in banana (Musa sp.) cv. Lady finger (AAB) and Cavendish cv. Williams (AAA). Lines derived from infected and healthy field plants had similar in vitro multiplication rates. BBTV-infected in vitro cultures displayed symptoms of stunting, leaf curling, chlorotic and green flecks, and poor root growth. Symptoms became milder with time, and were often difficult to discern in older, rapidly multiplying cultures. A triple antibody sandwich ELISA using polyclonal and monoclonal antibodies was very efficient for detecting BBTV in vitro. Symptomless, ELISA-negative plants arose in 10 out of 11 lines derived from BBTV-infected field plants and first appeared after 9 months continuous in vitro culture at a constant $28^{\circ} \mathrm{C}$. Meristem tip culture or heat therapy was not used. These plants remained symptomless and ELISA-negative after planting out in the glasshouse (individual plants checked for up to 16 months). The implications of this inconsistent transmission of BBTV for germplasm indexing and exchange are discussed.
\end{abstract}

Keywords: banana bunchy top virus, Musa, germplasm, micropropagation, tissue culture, ELISA.

\section{Introduction}

Banana bunchy top (BBT) is the most serious virus disease of bananas (Musa spp.). It occurs in Australia, many countries in Asia, a number of Pacific islands and several African countries (Frison and Putter 1989), and is frequently a serious constraint to production. Bananas are vegetatively propagated and are ideally suited to the process of micropropagation (tissue culture). This procedure offers many advantages, including uniformity of planting material and rapid multiplication, convenient conservation and exchange of germplasm, and freedom from most pests and diseases (Smith and Drew 1990; Smith and Hamill 1991). A serious constraint to the use of tissue culture, however, is the risk of concomitant transmission of viruses in the micropropagated plants. With increased international exchange of germplasm via tissue culture, regions such as Central and South America which are currently 'BBT-free' are placed at increased risk.

Banana bunchy top virus (BBTV, Drew et al. 1989, 1992; Ramos and Zamora 1990; Wu and Su 1991), cucumber mosaic virus (Gupta 1986) and banana 
streak virus (M.K. Smith, J.E. Thomas, K.G. Pegg, unpublished data) can be transmitted in tissue cultured banana plantlets. Ramos and Zamora (1990) reported the elimination of virus from a proportion of plantlets of BBTV-infected banana cv. Lakatan (AA) after heat therapy in vitro for 1 or 2 months at $40^{\circ} \mathrm{C} / 16 \mathrm{~h}$ photoperiod, $32^{\circ} / 8 \mathrm{~h}$. Similarly, Wu and $\mathrm{Su}$ (1991) obtained apparently BBTV-free plantlets of $\mathrm{cv}$. Cavendish (AAA) after in vitro heat therapy at a constant $35^{\circ} \mathrm{C}$ for 3 to 6 months. Drew et al. $(1989,1992)$ noted the appearance of symptomless plantlets in lines derived from symptomatic, BBTV-infected field plants after 12 months or more micropropagation at a constant $25^{\circ} \mathrm{C}$. A proportion of these plants later developed symptoms again when potted up in the glasshouse. However, other plantlets produced plants which have remained symptomless in field plantings for five years (Drew et al. 1992 and M. K. Smith, unpublished data). BBTV could not be detected in these symptomless field plants by ELISA, and the plants were susceptible to reinfection by the virus, indicating that they were virus-free and not BBTV-resistant somoclonal variants or symptomlessly infected. These BBTV-free plantlets were obtained without the use of either heat therapy or meristem tip culture.

This paper follows the transmission of BBTV through tissue culture and subsequent planting out in a number of lines each of Cavendish cv. Williams (AAA) and cv. Lady finger (AAB), with frequent monitoring of virus content by ELISA and symptomatology. The implications for germplasm indexing and exchange are discussed.

\section{Materials and Methods}

A total of seven $\mathrm{cv}$. Cavendish and four cv. Lady finger banana plants with typical symptoms of BBT disease (Frison and Putter 1989) were collected from a commercial plantation at Wappa Dam near Nambour, south-east Queensland and confirmed as infected with BBTV by triple antibody sandwich ELISA (Dietzgen and Thomas 1991). In this ELISA a mixture of monoclonal detecting antibodies BT-1 and BT-2 was also used at final dilutions of tissue culture supernatant in buffer of $4: 10$ and $1: 10$ respectively. Test samples were duplicated on all ELISA plates and the positive/negative threshold was defined as twice the mean absorbance value of the negative controls. Generally at least four replicates of an appropriate negative control (tissue culture plantlet or glasshouse-established plant) were included on each plate. Shoot tips were established in tissue culture and subcultured 11 times over a period of 18 months (Smith and Hamill 1991). All plants were transferred to a multiplication medium containing the salts and vitamins of Murashige and Skoog (1962) supplemented with $2.5 \mathrm{mg} / \mathrm{L}$ 6-benzylaminopurine, $20 \mathrm{~g} / \mathrm{L}$ sucrose and $8 \mathrm{~g} / \mathrm{L}$ Difco-Bitek agar and with $\mathrm{pH}$ adjusted to $6 \cdot 0$. The medium was autoclaved for $15 \mathrm{~min}$ at $121^{\circ} \mathrm{C}$ and $105 \mathrm{kPa}$. The rooting medium consisted of the ingredients described above without 6-benzylaminopurine. Plantlets were grown on multiplication medium except where specifically noted otherwise. Cultures were incubated at a constant $28^{\circ} \mathrm{C}$ with a $16 \mathrm{~h}$ photoperiod. Cool white fluorescent tubes provided a photon flux density at the culture surface of $80 \mu \mathrm{mol} \mathrm{m}^{-2} \mathrm{~s}^{-1}$. Multiplication rate was calculated as the average number of plantlets produced per explant per subculture over the course of 18 months. In vitro plantlets were periodically assessed for symptoms and tested by ELISA for BBTV. Plantlets on multiplication medium were destructively sampled for ELISA.

On two occasions, tissue culture plantlets were transferred to rooting medium, potted up in the glasshouse and periodically monitored for symptoms and tested by ELISA for the presence of BBTV. On the first occasion, plantlets had been in continuous tissue culture for 10 months ( 7 subcultures) and were monitored for a further 16 months in the glasshouse. On the second occasion, plantlets had been in continuous tissue culture for 15 months ( 9 subcultures) and were monitored for a further 12 months in the glasshouse.

Rapidly proliferating cultures of uninfected and BBTV-infected lines on multiplication nedium were assessed for symptom expression using a 'blind test'. An apparently virus-free 
selection of line 8 and BBTV-infected lines 4 and 7 from the current work (continuous 18 months in vitro) and virus-free cultivars Puerto Rican Dwarf Plantain (AAB), Dwarf Cavendish (AAA), Laknau (AAB) and Musa jackeyi (continuous 1-3 years in vitro) from the Maroochy germplasm collection, were used. Without prior knowledge of the identity of the lines, four researchers, all experienced in indexing tissue-cultured bananas, independently assessed each of the seven lines for symptoms. All lines were then indexed by ELISA.

\section{Results}

Symptoms and Presence of Virus through Tissue Culture

Early subcultures (1-6)

The symptoms of BBTV infection shown by in vitro plantlets of cv. Cavendish and $\mathrm{cv}$. Lady finger were similar. Plantlets were generally a little chlorotic and less vigorous than comparable healthy controls. Occasional green flecks on the leaf sheaths and chlorotic to translucent flecks on the leaves were visible, and dark streaks were sometimes present on the older leaves. All plantlets of all 11 lines showed some degree of symptom expression during these subcultures (approx. first 6 months). The virus was readily detectable in all these plants by ELISA. The results shown in Table 1 for plantlets after three cycles of subculturing on multiplication medium and 4 months continuous in vitro culture are typical for these early subcultures.

Table 1. Detection of BBTV in micropropagated bananas by ELISA with monoclonal antibodies after 3 cycles of subculturing and continuous in vitro culture for 4 months

\begin{tabular}{|c|c|c|c|}
\hline \multirow[t]{2}{*}{ Sample } & \multirow[b]{2}{*}{ Line } & \multicolumn{2}{|c|}{$A_{405 \mathrm{~nm}} \mathrm{C}$} \\
\hline & & BT-1 & $\mathrm{BT}-2$ \\
\hline \multirow[t]{7}{*}{ Cavendish } & 1 & 0.71 & $0 \cdot 88$ \\
\hline & 3 & $0 \cdot 70$ & $1 \cdot 25$ \\
\hline & 4 & 0.83 & $1 \cdot 11$ \\
\hline & 5 & $1 \cdot 00$ & $1 \cdot 29$ \\
\hline & 6 & 0.80 & $0 \cdot 81$ \\
\hline & 7 & 0.49 & 0.55 \\
\hline & 8 & $0 \cdot 72$ & 0.88 \\
\hline \multirow[t]{4}{*}{ Lady finger } & 9 & $0 \cdot 45$ & $0 \cdot 61$ \\
\hline & 10 & $0 \cdot 45$ & 0.80 \\
\hline & 11 & $0 \cdot 62$ & 0.93 \\
\hline & 12 & $0 \cdot 47$ & $0 \cdot 75$ \\
\hline Positive control ${ }^{\mathrm{A}}$ & & $0 \cdot 12$ & $0 \cdot 70$ \\
\hline \multicolumn{4}{|l|}{ Negative controls ${ }^{B}$} \\
\hline Glasshouse & & $0 \cdot 02$ & 0.01 \\
\hline Tissue culture & & 0.02 & 0.02 \\
\hline
\end{tabular}

A BBTV-infected field plants.

${ }^{B}$ Glasshouse grown (cv. Cavendish) and micropropagated (cvv. Cavendish and Lady finger) healthy bananas.

${ }_{C}$ Absorbance at $405 \mathrm{~nm}$ using a triple antibody sandwich ELISA incorporating monoclonal antibodies BT-1 and BT-2. Values shown are the means of duplicated test samples (except negative controls which were each replicated four times). Positive reactions are shown in bold. 
Later subcultures (7-11)

At the seventh subculture, plantlets had been in continuous in vitro culture for 9 months. Some symptomless plantlets were apparent in Cavendish lines 3,5 and 8 and Lady finger line 11 and constituted c. $8-14 \%$ of the total plantlets in those lines. A total of 38 plantlets growing on multiplication medium and representing nine of the eleven lines from subculture 7 , were individually examined for symptoms and indexed for BBTV by ELISA. Plantlets with and without symptoms were selected from each line. Symptomatology and ELISA results correlated well (Table 2). The virus was not detected by ELISA in 11 of 12 symptomless plants. $\left(A_{405 \mathrm{~nm}}\right.$ values of $0.02-0.04$ compared to positive samples of $0 \cdot 6->2$ ) and at a very low level in the remaining symptomless plant (Cavendish 8, plantlet 'd'; $A_{405 \mathrm{~nm}} 0 \cdot 08$ ). The virus was not detected in one plantlet that was too small for reliable symptom assessment. The virus was detected in all plantlets showing clear symptoms and in several too small to be reliably visually assessed $\left(A_{405 \mathrm{~nm}}\right.$ values of $0 \cdot 6->2$, compared to negative control of 0.02 ). These included all plantlets tested of Cavendish lines 1, 4,6 and 7 and Lady finger line 12, as well as all symptomatic plantlets of Cavendish lines 3, 5 and 8 and Lady finger line 11. As shown in Table 2, Cavendish 8 plantlet 'a' gave a borderline ELISA result and plantlet ' $d$ ' gave a weak positive result. When these samples were retested plantlet 'a' was clearly negative $\left(A_{405 \mathrm{~nm}} 0 \cdot 03\right)$ and plantlet ' $\mathrm{d}$ ' was again weakly positive $\left(A_{405 \mathrm{~nm}} 0.07\right)$ compared to the negative control $\left.A_{405 \mathrm{~nm}} 0.03\right)$.

Table 2. Symptomatology and presence of BBTV in plantlets of lines of cv. Cavendish and cv. Lady finger containing symptomless plantlets in tissue culture at subculture 7 after 9 months continuous in vitro culture

\begin{tabular}{|c|c|c|c|c|c|c|c|}
\hline Line & Plantlet & Symptoms ${ }^{\mathrm{C}}$ & $A_{405 \mathrm{~nm}} \mathrm{D}$ & Line & Plantlet & Symptoms $^{C}$ & $A_{405 \mathrm{~nm}^{\mathrm{D}}}$ \\
\hline \multirow[t]{7}{*}{ Cavendish 3} & & & & Cavendish 8 & & & \\
\hline & a & + & $1 \cdot 15$ & & a & - & 0.04 \\
\hline & $\mathrm{b}$ & - & 0.03 & & $\mathrm{~b}$ & + & $1 \cdot 38$ \\
\hline & $c$ & + & $1 \cdot 53$ & & $\mathrm{c}$ & + & 0.92 \\
\hline & d & - & 0.02 & & d & - & 0.08 \\
\hline & $\mathbf{e}$ & - & 0.02 & & e & - & 0.02 \\
\hline & & & & & f & - & 0.01 \\
\hline
\end{tabular}

Cavendish 5

$\begin{array}{lll}\mathrm{a} & + & \mathbf{1 . 2} \\ \mathrm{b} & + & \mathbf{1 . 3} \\ \mathrm{c} & + & \mathbf{1 . 3} \\ \mathrm{d} & - & 0.02 \\ \mathrm{e} & - & 0.02 \\ \mathrm{f} & - & 0.02\end{array}$

Lady finger 11

$1 \cdot 36$

$1 \cdot 34$

0.02

0.02

$\begin{array}{lccc} & \mathrm{a} & + & \mathbf{1 . 0 6} \\ & \mathrm{b} & - & 0.02 \\ & \mathrm{c} & - & 0.01 \\ & \mathrm{~d} & - & 0.02 \\ \text { Positive control }^{\mathrm{A}} & \mathrm{e} & ? & 0.02 \\ \text { Negative control }^{\mathrm{B}} & & + & \mathbf{0 . 8 4} \\ & & - & 0.02\end{array}$

A BBTV-infected glasshouse plant, cv. Cavendish.

${ }^{B}$ Healthy glasshouse plant, cv. Cavendish.

$\mathrm{C}+$, symptoms present, as described in text. -, no symptoms apparent. ?, plantlets too small for reliable assessment.

$D$ Absorbance at $405 \mathrm{~nm}$ using triple antibody sandwich ELISA incorporating monoclonal antibodies BT-1 and BT-2. Values shown are the means of duplicated test samples (except for negative controls which were each replicated four times). Positive reactions are shown in bold.

Plantlets of all 11 lines on rooting medium were similarly examined for symptoms and ELISA-tested after subculture 7 (10 months continuous in vitro culture), subculture 9 (15 months continuous in vitro culture, except for Lady finger line 9), and subculture 11 (25 months in continuous in vitro culture). At 
subcultures 7 and 9 there was complete correlation between presence of symptoms and detection of BBTV by ELISA. The virus was detected in all 26 and 25 plantlets with symptoms and not in any of the 9 and 29 symptomless plantlets respectively. At subculture 11 , the virus was detected in all 42 plantlets with symptoms, but also in 6 apparently symptomless plantlets. No virus was detected in the remaining 36 symptomless plants.

\section{Multiplication rates}

The ability of BBTV-infected plants to grow and multiply was unaffected by virus infection and multiplication rates were fairly uniform within cultivars, and were as good or better for the BBTV-infected lines as for uninfected controls (Table 3 ). The rate for Cavendish uninfected controls ranged from $\times 2 \cdot 3-2 \cdot 6$ compared to $\times 2 \cdot 7-3.5$ for infected lines, whilst for Lady finger the rate for uninfected controls was $\times 1 \cdot 2-1 \cdot 7$ compared to $\times 1 \cdot 5-1.8$ for infected lines.

Table 3. Multiplication rate of BBTV-infected micropropagated bananas and subculture stage at which symptomless plantlets arose

\begin{tabular}{|c|c|c|c|}
\hline Line & & $\begin{array}{l}\text { Multiplication } \\
\text { rate }^{\mathrm{A}}\end{array}$ & $\begin{array}{c}\text { Subculture when } \\
\text { symptomless plantlets } \\
\text { arose }\end{array}$ \\
\hline \multicolumn{4}{|l|}{ Cavendish } \\
\hline & 1 & $3.5(0.9)$ & 8 th, 10th \\
\hline & 3 & $3 \cdot 4(0 \cdot 7)$ & 7 th, 8 th, 10 th \\
\hline & 4 & $3 \cdot 4(0 \cdot 5)$ & 8 th, 9 th, 10 th \\
\hline & 5 & $3 \cdot 5(0 \cdot 7)$ & 7 th \\
\hline & 6 & $2 \cdot 7(0 \cdot 8)$ & 10 th \\
\hline & 7 & $3 \cdot 2(0 \cdot 8)$ & 10 th \\
\hline & 8 & $3 \cdot 2(1 \cdot 0)$ & 7th, 8th, 9th, 11th \\
\hline \multirow{3}{*}{ Cavendish uninfected controls } & A & $2 \cdot 3(0 \cdot 8)$ & - \\
\hline & B & $2 \cdot 6(1 \cdot 0)$ & - \\
\hline & $\mathrm{C}$ & $2 \cdot 5(0 \cdot 8)$ & - \\
\hline \multicolumn{4}{|l|}{ Lady finger } \\
\hline & 9 & $1 \cdot 5(0 \cdot 3)$ & $-^{B}$ \\
\hline & 10 & $1.5(0 \cdot 3)$ & 8 th \\
\hline & 11 & $1 \cdot 8(0 \cdot 4)$ & 7 th, 8 th \\
\hline & 12 & $1 \cdot 8(0 \cdot 2)$ & $8 \mathrm{th}$ \\
\hline \multirow{3}{*}{ Lady finger uninfected controls } & A & $1 \cdot 2(0 \cdot 3)$ & - \\
\hline & B & $1.6(0 \cdot 5)$ & - \\
\hline & $\mathrm{C}$ & $1 \cdot 7(1 \cdot 0)$ & 一 \\
\hline
\end{tabular}

$\bar{A}$ Values are the mean multiplication rate of 12 subculture events for BBTVinfected lines Cavendish 1, 3-8 and Lady finger 9-12. Three uninfected lines for Cavendish and Lady finger were included as controls. Values in parentheses are standard errors.

${ }^{B}$ Symptomless plantlets did not arise in this line during the course of the experiment.

\section{Symptoms}

The symptoms in infected plantlets became progressively milder with time. In the early subcultures they were usually readily apparent, but after 12 months continuous in vitro culture were often difficult to detect. Eighteen-month-old infected cultures which were proliferating rapidly were virtually indistinguishable 
from non-infected bananas from a range of cultivars and accessions which were proliferating in a similar mode. These plantlets tended not to produce a recognizable pseudostem, and they frequently had a paler colour. Even for researchers familiar with BBTV-infected micropropagated plants, 'blind tests' with rapidly proliferating cultures of known uninfected and BBTV-infected banana lines showed that visual identification of the infected lines was very difficult or impossible. Of the four researchers tested, only one was able to correctly identify the two mildly symptomatic, infected plantlets, though even this individual was uncertain of the symptom status of one of the five healthy plantlets. ELISA tests on these seven plantlets, however, were clear cut, with $A_{405 \mathrm{~nm}}$ values of $>2$ for infected plantlets and 0.02 to 0.04 for healthy plantlets. However, when the infected cultures were not proliferating rapidly (for example, when growing on a rooting medium), the 'infected' plantlets became easier to distinguish, with stunted, small, tightly curled leaves, chlorotic streaks on the leaves and dark almost black streaks on senescing leaves, compared to the larger more vigorous healthy plantlets with non-curled dark green leaves. The root systems of healthy plantlets on rooting medium were far more vigorous than those of the infected plantlets.

\section{Growing on of Symptomless Micropropagated Plants}

After 7 cycles of subculture, symptomless, ELISA negative plantlets from the following lines, on rooting medium, were established in the glasshouse: Cavendish 3 (2 plantlets), 5 (1 plantlet), 8 (2 plantlets) and Lady finger 11 (2 plantlets). One plant of line 8 died after 9 months, at which stage it was still symptomless and ELISA-negative. All other plants remained symptomless, and did not contain detectable levels of BBTV when tested at intervals for 16 months.

After a total of 9 cycles of subculture, 41 plantlets from 7 lines were transferred from rooting medium and potted up in the glasshouse. Ten plantlets did not establish and of these, 9 were BBTV-infected Cavendish or Lady finger. The remaining plant was a symptomless, ELISA-negative Cavendish. Of the 31 plantlets that were successfully established, 27 were symptomless and ELISA-negative in tissue culture, and represented Cavendish lines 3, 4, 5 and 8, and Lady finger lines 11 and 12. These plants retained their symptomless, ELISA-negative status when checked after a further 4 months (one plant not tested), 9 months and 12 months (one plant died prior to final testing). The remaining four tissue-cultured plantlets that were established were ELISA-positive with typical BBT symptoms and were used as positive controls for this experiment. This group comprised Cavendish line 7 (2 plantlets) Lady finger line 11 (1 plantlet) and Lady finger line 12 (1 plantlet). These plants developed typical BBT symptoms when established in the glasshouse and gave positive ELISA reactions for BBTV whenever tested.

\section{Discussion}

This work with Cavendish cv. Williams and cv. Lady finger confirms previous findings that BBTV is readily transmitted through the micropropagation process in a number of banana cultivars including cv. Lakatan (Ramos and Zamora 1990), Cavendish cv. Mons Mari (Drew et al. 1989, 1992) and cv. Cavendish (Wu and Su 1991). 
The finding of Drew et al. $(1989,1992)$ that plants apparently free of BBTV can arise from initially BBTV-infected cultures through normal tissue culture procedures was supported and further examined in the current work. Unequivocal proof that a plant is virus-free is not attainable, as all forms of indexing are limited by the sensitivity and practicality of the particular tests used. However, we consider that the extended periods of observation of the symptomless plants and the ELISA indexing undertaken strongly suggests that the symptomless plants are in fact virus-free. In our work meristem tip culture was not utilized, cultures were grown at a constant $28^{\circ} \mathrm{C}$ (i.e. heat therapy was not applied) and chemotherapy treatments were not used. Symptomless plants arose in the majority of lines examined (10 of 11) after prolonged in vitro culture (at least 7 months) and arose on a number of separate occasions in five of the lines. It is hypothesized that the distribution and movement of BBTV in actively growing meristematic tissue is irregular and that sub-culturing can by chance, on occasions, result in the selection of virus-free meristems. In our work all symptomless, ELISA-negative plants that were potted up retained their apparently virus-free status for up to 16 months after planting out in the glasshouse (the maximum period of observation).

The symptoms of BBT in in vitro plants became progressively milder with time, and were especially difficult to identify in rapidly proliferating material. This phenomenon makes the use of symptomatology as the sole criterion of infection of in vitro plants a very unreliable practice. It is likely that the failure of Drew et al. (1989) to recognize symptoms of BBT at any stage in vitro in their work in part reflects the amelioration of symptoms described in this work. Dark green and chlorotic leaf flecks are often manifest in vitro, but at times can be very subtle and difficult to detect.

ELISA was shown to be a very reliable method for the detection of BBTV in micropropagated plants. It was successful in detecting the virus in all symptomatic plantlets examined and also in several near-symptomless or symptomless plantlets. With a single exception, all infected plantlets examined gave strong positive reactions. The exception was a symptomless in vitro plantlet that when tested and retested, gave positive ELISA absorbance values, but only $3-4 \times$ the negative controls. The plant had been destructively sampled and so could not be grown on to confirm its virus status.

The spontaneous appearance of symptomless, virus-free plantlets seems not to have occurred in the work of Ramos and Zamora (1990). They obtained virus-free plants only from a combination of heat therapy $\left(40^{\circ} \mathrm{C} / 16 \mathrm{~h}\right.$ day, $32^{\circ} \mathrm{C} / 8 \mathrm{~h}$ night $)$ for 4 or 8 weeks, followed by meristem tip culture. With hundreds of plantlets, heat therapy alone or untreated controls all failed to produce virus-free plantlets. Similarly, Wu and $\mathrm{Su}$ (1991) failed to obtain BBTV-free in vitro plantlets with heat therapy alone $\left(40^{\circ} \mathrm{C} / 16 \mathrm{~h}\right.$ day, $30^{\circ} \mathrm{C} / 8 \mathrm{~h}$ night $)$ for periods of 4 to 12 weeks. BBTV was less readily aphid-transmitted though from $35 \mathrm{~cm}$ high plants subjected to the same temperature regime, suggesting that virus titre was suppressed. By contrast, cultures maintained at a constant $35^{\circ} \mathrm{C}$ produced some symptomless plantlets by 3 months, and after 6 months, 5 of 11 cultures had produced some symptomless, ELISA-negative plantlets. Drew et al. (1989) also reported symptomless plants derived from cultures maintained in vitro at $25^{\circ} \mathrm{C}$ for 16 months, but not at 12 months. In the present work, cultures were maintained 
at $28^{\circ} \mathrm{C}$ and symptomless plantlets were first apparent at 7 months. It is likely that elevated temperatures are not essential for virus-elimination and that the $35^{\circ} \mathrm{C}$ used by $\mathrm{Wu}$ and $\mathrm{Su}$ (1991) may simply allow the process to happen more quickly.

The implications of this and previous work (Drew et al. 1989, 1992; Ramos and Zamora 1990; Wu and Su 1991) for the indexing, conservation and exchange of germplasm and for the rapid micropropagation of planting material are fourfold:

(i) BBTV is readily transmitted via micropropagation.

(ii) Symptomatology is unreliable as a means of assessing the BBTV status of in vitro cultures.

(iii) Planting material should be indexed for BBTV immediately prior to establishment in tissue culture. Otherwise, the eventual appearance of a proportion of symptomless, apparently virus-free plantlets in an initially infected line could confuse subsequent indexing of this line. If only a proportion of in vitro plantlets in a line is indexed, virus-free plantlets could be selected for indexing, allowing virus-infected plantlets to go undetected.

If indexing prior to establishment in tissue culture cannot be achieved, then plantlets should be chosen so as to be as representative of the line as possible and to include samples from all subculturing lines. However, regardless of the sampling procedure in the latter case, indexing security will be compromised.

(iv) Tissue culture shows great promise as a means to free valuable germplasm lines of BBTV-infection, either by heat therapy and meristem culture (Ramos and Zamora 1990) or extended in vitro culture (Wu and $\mathrm{Su} 1991$, present work).

\section{Acknowledgements}

This work was funded by the Horticultural Research and Development Corporation, the Banana Industry Protection Board and the Australian Centre for International Agricultural Research. We thank Eric Gall for assistance with the collection of BBTV-infected banana plants and Ralf Dietzgen for helpful discussions.

\section{References}

Dietzgen, R. G., and Thomas, J. E. (1991). Properties of virus-like particles associated with banana bunchy top disease in Hawaii, Indonesia and Tonga. Australasian Plant Pathology 20, 161-5.

Drew, R. A., Moisander, J. A., and Smith, M. K. (1989). The transmission of banana bunchy top virus in micropropagated bananas. Plant Cell, Tissue and Organ Culture 16, 187-93.

Drew, R. A., Smith, M. K., and Andersen, D. W. (1992). Field evaluation of micropropagated bananas derived from plants containing banana bunchy top virus. Plant Cell, Tissue and Organ Culture 28, 203-5.

Frison, E. A., and Putter, C. A. J. (Eds) (1989). FAO/IBPGR technical guidelines for the safe movement of Musa germplasm. Food and Agriculture Organisation of the United Nations, Rome/International Board for Plant Genetic Resources, Rome.

Gupta, P. (1986). Eradication of mosaic disease and rapid clonal multiplication of bananas and plantain through meristem tip culture. Plant Cell, Tissue and Organ Culture 6, 33-9.

Murashige, T., and Skoog, F. (1962). A revised medium for rapid growth and bioassays with tobacco tissue cultures. Physiologia Plantarum 15, 473-97. 
Ramos, C. S., and Zamora, A. B. (1990). Elimination of banana bunchy top infection from banana (Musa sp. cv. Lakatan) by heat pre-treatment and meristem culture. Philippine Journal of Crop Science 16, 119-23.

Smith, M. K., and Hamill, S. D. (1991). Use of tissue culture for the propagation and improvement of bananas and plantains. In 'Banana Diseases in Asia and the Pacific.' (Eds R. V. Valmayor, B. E. Umali and C. P. Bejosano.) Proceedings of a technical meeting on diseases affecting banana and plantain in Asia and the Pacific, Brisbane, Australia 15-18 April 1991. INIBAP, pp. 158-73.

Smith, M. K., and Drew, R. A. (1990). Current applications of tissue culture in plant propagation and improvement. Australian Journal of Plant Physiology 17, 267-89.

Wu, R. Y., and Su, H. J. (1991). Regeneration of healthy banana plantlets from banana bunchy top virus-infected tissues cultured at high temperature. Plant Pathology 40, 4-7.

Manuscript received 8 March 1994, accepted 25 October 1994 
. 